\title{
Special issue: Academy of Marketing Conference 2016: radical financial services marketing
}

\author{
Julie Robson $^{1} \cdot$ Kathryn Waite ${ }^{2}$
}

(C) Macmillan Publishers Ltd 2017

In this special issue, we are pleased to present research from academics who presented at the Academy of Marketing conference 2016 (AM2016) hosted by Newcastle Business School. The theme of the AM2016 conference was radical marketing, which was defined as spanning both the traditional and truly innovative. Thus, in this special issue, we present a range of papers that contribute to the idea of radical financial services marketing. This special issue is the third in an ongoing series which began with papers from contributors to the Academy of Marketing Conference 2014 in Bournemouth (issue published in 2015).

The term radical marketing can be interpreted as being both foundational and progressive. The Latin word "radix" means roots, so a radical financial services marketing approach may draw upon the "roots" of established marketing theory to provide an incremental "green shoots" development in thought and practice. However, the use of the term radical also can denote political radicalism which focuses on challenging and changing traditional structures and value systems in response to societal change. Thus, radical financial services marketing may present a revolutionary change in thought and practice in order to address emerging social issues.

In this issue, we have two papers that are "rooted" in the established theory of service quality; these papers offer "green shoots" thinking on the impact of culture upon the

Julie Robson

jrobson@bournemouth.ac.uk

Kathryn Waite

k.waite@hw.ac.uk

1 University of Bournemouth, Bournemouth, UK

2 Heriot-Watt University, Edinburgh, UK customer evaluation of financial services. In their paper, Yalley and Agyapong develop a new instrument (GhanQual) to provide a crossvergence perspective on measuring service quality. Crossvergence theory (Ralston et al. 1997) argues that convergent and divergent value systems can be blended, and GhanQual unites multicultural and culturally specific approaches to service quality management. This paper provides a starting point for developing further crossvergent approaches to financial services marketing measurement. In the second paper, Abdullrahim and Robson use an extended SERVQUAL model to identify and compare the importance of service quality to British Muslim consumers with an Islamic or non-Islamic bank account in a non-Muslim country. They identify five dimensions of service quality that differ in structure and content from the original scale and also vary in the degree of importance placed upon them by customers. The results provide insight into bank choice and evaluation amongst Muslim customers living in a non-Muslim cultural context and in particular highlight the importance of "Islamic Tangibles" which meet faith preferences. There are clear opportunities for the published scale, which was developed within the UK, to be re-examined in different national settings.

Our third paper examines trust, which is another concept that is firmly established with the marketing discipline and in particular within financial services marketing. In a financial services consumption context, trust and confidence may only be established as a result of direct experience. Financial services customers have to place trust in the capability and professionalism of organisations and their employees due to the asymmetries of information and expertise that characterise many financial services products (Harrison 2000). In their paper, Moin, Devlin and McKechnie examine how trust in financial services varies 
according to individual trust disposition. Their detailed and systematic analysis provides a strategic segmentation of the consumer mass market and offers useful insights to financial services marketers charged with designing financial products and developing trust building strategies. They note that the small sample size and the cross-sectional administration of the research instrument means that additional study is needed and has the potential to develop new theories within the intersections of trust, services and relationship marketing.

The final two papers in this special issue are radical in their focus on alternative and new ideas of financial services marketing in a time of significant social change, particularly in the context of debt and obtaining credit. Unsecured consumer debt in the UK (which includes credit cards and car loans) grew by $10.8 \%$ in the year to November 2016 to $£ 192.2 \mathrm{bn}$, the fastest rate of growth in more than 11 years (Bank of England 2017). Taking a radical approach to what can be classified as a financial service, Lomax and Edwards examine customer perceptions of pawnbroking. Pawnbrokers are not considered a typical financial service but are an established form of money-lending and many have highstreet premises. Lomax and Edwards identify that pawnbroking is considered an "unmentionable" financial service. This qualitative study finds that amongst non-users of the service, there exists minimal understanding of the service delivery process, feelings of latent stigma and narratives that draw on broadcast media stereotypes. In contrast, users of pawnbroking report service satisfaction. Moreover, independent evaluation by BBC Moneybox finds pawnbroking to be more cost-effective than an unauthorised bank overdraft or a payday loan. The implications of this work are that consumers discount and disassociate themselves from pawnbroking services as a source of credit not on rational decision-making terms but as a result of ignorance and negative affect. In order to address this situation, the authors recommend that information flows are increased and that the terminology and image of the industry is reframed to show greater balance. Future research in this area might include experiments that test different message content and sources to see whether an attitudinal shift is possible.

Our final paper by Brown, Wappling, Black and Woodruffe-Burton offers a radical innovation in modelling consumer choice between alternative credit sources that contrasts with established approaches to the "spiral of debt". Using Critical Consumer Theory (Arnould and Thompson 2005) as a theoretical lens, they explore how UK consumers manage and select alternative credit sources (i.e. payday loans, logbook loans, pawning). Based on their empirical findings, Brown et al. develop the Orbit of Consumer Credit Choices. The model identifies a series of orbit rings that depict the nonlinear movement between different credit sources. The Orbit model shows how consumers migrate to the next credit source once they have exhausted an existing source of credit. The authors also discuss the impact of emotions on decision-making as consumers move between and select credit sources. This research presents an alternative view to the widely accepted linear modelling of progressive debt. Future research could test and extend this model in both different national and product choice contexts.

The research in this Special Issue indicates the depth and breadth of the financial services marketing discipline and the important role played by the Journal of Financial Services Marketing as an outlet for disseminating this "radical" knowledge. All the submissions were accepted after a double-blind peer review based on rigour, validity and focus upon financial services marketing. We would like to extend our thanks and acknowledgements to our panel of anonymous reviewers for their knowledge, skill, patience and dedication to this issue as we recognise the considerable demands upon their time. We look forward to the 2017 Academy of Marketing Conference at Hull University Business School and to enjoying a further round of stimulating and insightful financial services marketing research.

\section{References}

Arnould, E.J., and C.J. Thompson. 2005. Consumer culture theory (CCT): twenty years of research. Journal of Consumer Research 31 (4): 868-882.

Bank of England. 2017. Quarterly bulletin available online at http:// www.bankofengland.co.uk/publications/Documents/quarterlybul letin/2017/q1/qbapp.pdf. Accessed 23 March 2017.

Harrison, T. 2000. Financial Services Marketing. Financial Times. London: Prentice Hall.

Ralston, D.A., D.H. Holt, R.H. Terpstra, and Y. Kai-Cheng. 1997. The impact of national cultures and economic ideology on managerial work values: a study of the United States, Russia, Japan, and China. Journal of International Business Studies 28 (1): 177-207. 